\title{
CHILDHOOD LEUKAEMIA AND SOCIOECONOMIC STATUS: WHAT IS THE EVIDENCE?
}

\author{
Martin Adam, Cornelia E. Rebholz, Matthias Egger, Marcel Zwahlen and Claudia E. Kuehni* \\ Swiss Childhood Cancer Registry, Institute of Social and Preventive Medicine, University of Bern, \\ Finkenhubelweg 11, Bern CH-3012, Switzerland
}

\begin{abstract}
The objectives of this systematic review are to summarise the current literature on socioeconomic status (SES) and the risk of childhood leukaemia, to highlight methodological problems and formulate recommendations for future research. Starting from the systematic review of Poole et al. (Socioeconomic status and childhood leukaemia: a review. Int. J. Epidemiol. 2006;35(2):370-384.), an electronic literature search was performed covering August 2002-April 2008. It showed that (1) the results are heterogeneous, with no clear evidence to support a relation between SES and childhood leukaemia; (2) a number of factors, most importantly selection bias, might explain inconsistencies between studies; (3) there is some support for an association between SES at birth (rather than later in childhood) and childhood leukaemia and (4) if there are any associations, these are weak, limited to the most extreme SES groups (the 10-20\% most or least deprived). This makes it unlikely that they would act as strong confounders in research addressing associations between other exposures and childhood leukaemia. Future research should minimise case and control selection bias, distinguish between different SES measures and leukaemia subtypes and consider timing of exposures and cancer outcomes.
\end{abstract}

\section{INTRODUCTION}

Numerous epidemiological studies have reported higher rates of mortality and morbidity among infants, children and adults of lower socioeconomic status (SES), defined at an individual or an area level ${ }^{(1-3)}$. It has been suggested that childhood leukaemia might be one of the rare exceptions, being reportedly more common among children of high $\mathrm{SES}^{(4)}$. This has led to speculations about a range of potential aetiological factors linked with affluence and modern lifestyle, acting via altered host susceptibility or environmental exposures.

A systematic review by Poole et al. ${ }^{(5)}$, summarising the papers published through August 2002, concluded that the results of these studies were heterogeneous and varied by place, time, study design and measure of SES utilised. Many of the studies in this review were rather old, based on small or selected populations, or had other methodological problems. Since August 2002, several well-conducted, large-scale population- or registry-based studies have appeared, addressing several issues highlighted by Poole et al., so that it seems timely to review their results.

The aims of this article, which was written in the context of the International Workshop on Risk Factors for Childhood Leukaemia (Berlin, 5-7 May 2008), are to summarise the current evidence on SES and risk of childhood leukaemia, to highlight methodological problems and biases and to give recommendations for future research.

*Corresponding author: kuehni@ispm.unibe.ch

\section{Importance of SES in health research}

SES, also called socioeconomic position or social class, is a commonly used concept in health research, which refers to the social and economic factors that influence what positions individuals or groups hold within a society ${ }^{(6)}$. Measuring SES is important in order to describe socioeconomic differentials in health, to inform health policy, to monitor changes over time and across different geographical regions and to evaluate whether policy targets to diminish health inequalities have been reached. A second purpose for measuring SES relates to explaining the mechanisms through which SES generates health differences. This requires a thorough investigation of different indicators of SES to examine whether one particular measure of SES relates more closely to a particular outcome. Also, the life course approach offers considerable opportunity to explore causal pathways ${ }^{(7-9)}$. This requires measurements of SES at different points in time during the life course, e.g. pregnancy/birth, infancy, childhood and adulthood. A third important reason to consider SES in health research is to statistically adjust for socioeconomic circumstances when another exposure is the main focus of interest. Confounding, the situation in which an apparent effect of an exposure on risk is explained by its association with other factors, is an important cause of spurious or misleading associations in observational epidemiology. SES is a common and important confounding factor: many exposures and diseases are socially patterned and there is a need to 


\section{SES AND CHILDHOOD LEUKAEMIA}

control for socioeconomic circumstances in order to obtain the 'independent' effect of the exposure of interest. Composite indicators, which capture several aspects of SES, have particularly been useful in this situation, as the researcher is not specifically interested in the effect of each component of the index, only in its control as a confounder.

\section{Measures of SES}

Indicators of SES have recently been reviewed by Galobardes et al. ${ }^{(10,11)}$ As these authors stress, there is no single best indicator of SES suitable for all study aims and applicable at all time points in all settings. Each indicator measures different, often related aspects that may be more or less relevant to different health outcomes and at different stages in the life course. The measures that are relevant to childhood cancer and might be associated with leukaemia in particular are briefly summarised below.

\section{Education}

Education is a frequently used indicator for SES in epidemiology and attempts to capture the knowledgerelated assets of a person. It represents the long-term influences of early life circumstances on adult health, as well as the influence of adult resources (e.g. through employment status) on health ${ }^{(12)}$. For children, parental education, particularly maternal education, reflects the family's knowledge related to healthy lifestyles, adequate symptom reporting and the use of the health-care system ${ }^{(13)}$. Education is comparatively easy to measure in self-administered questionnaires, with a high response rate, and is relevant to people regardless of age or working circumstances, unlike occupation and other SES indicators ${ }^{(14)}$. Also, the collection of information on education will often be less sensitive than other SES indicators relating to material resources such as income. A disadvantage of education level as an indicator of SES is that its meaning varies for different birth cohorts and in different geographical settings. For instance, the changing educational opportunities for women over recent decades have to be taken into account in epidemiological studies. Furthermore, education is specific to the educational system adopted in a country.

\section{Occupation}

Occupation-based indicators of SES are widely used. Occupation represents the notion of SES as a reflection of a person's place in society related to their social standing, income and intellect. Occupation may also reflect social networks, work-based stress, control and autonomy and thereby affect health outcomes through psychosocial processes. Finally, it may reflect specific toxic environmental or work task exposures such as physical demands. An important strength of occupational measures is their availability in many routine data sources, including census data and death certificates. One of the most important limitations of occupational indicators is that they cannot be readily assigned to people who are not currently employed. Groups commonly excluded are retired people, people whose work is inside the home (mainly affecting women), the unemployed, students and people working in unpaid, informal or illegal jobs. As with education, occupation may have different meanings for different birth cohorts and in different geographical settings.

\section{Income}

Income is the indicator of SES that most directly measures the material resources. It is implausible that money in itself directly affects health; thus, it is the conversion of money and assets into healthenhancing commodities and services via expenditure that is the more relevant concept for interpreting how income affects health. Income exhibits a 'doseresponse' association with mortality ${ }^{(15)}$, a cumulative effect over the life course ${ }^{(16)}$ and is the SES indicator that can change most on a short-term basis. Income is arguably the best single indicator of material living standards; however, it is a sensitive issue and people may be reluctant to provide such information. Also, information on income is usually not available in routine data sources.

\section{Housing}

Housing characteristics measure material aspects of socioeconomic circumstances ${ }^{(17)}$ and are frequently used as measures of SES. They are comparatively easy to collect or available from routinely collected data, including censuses. Crowding in households refers to the number of people per room and is usually measured as the number of people per bedroom. Overcrowding is then defined as being above a specific threshold (commonly more than two people per room). The main disadvantage of housing indicators is that they are likely to be specific to the period and setting where they were developed $^{(10,11,17)}$.

\section{Area-level indicators}

Ecological, or area-level, indicators are also used as measures of SES. Most commonly, these are aggregated from individual level or small area data, usually from census or other administrative databases. They can be used as a proxy for the SES of the people living in those areas. In many studies, one or more aggregate area measures, e.g. proportion of unemployed, proportion in blue collar or manual 


\section{ADAM ET AL.}

occupations, proportion with higher education in an area, are used with no attempt to combine measures into a composite score. In Britain, a number of composite area-level measures of SES have been developed, including the Jarman Index ${ }^{(18)}$, the Carstairs Index ${ }^{(19)}$ and the Townsend Index ${ }^{(20)}$, and used for examination of socioeconomic differentials across regions and electoral wards ${ }^{(21,22)}$. More recently, an Index of Multiple Deprivation (IMD) has been developed by the British Government and regularly updated (IMD 2000, IMD 2004) ${ }^{(23,24)}$. In the USA, similar measures have been used ${ }^{(25-30)}$. Area-based measures have proved particularly useful in the exploration of mortality differentials in women and children, for whom meaningful individual-level measures of socioeconomic position are often not available ${ }^{(31)}$.

\section{Older literature on SES and childhood leukaemia (through August 2002)}

The older literature relating to SES and childhood leukaemia has been reviewed in 1985 by Greenberg and Shuster ${ }^{(4)}$ (including studies published through 1982), and in 2006 by Poole et al. ${ }^{(5)}$ (including the literature through August 2002). Greenberg and Shuster classified five of the six studies published at this time as showing an increased risk of childhood leukaemia in children of higher SES. This view has often been cited since and led to numerous speculations about possible risk factors associated with a more affluent lifestyle, despite the fact that many studies published since 1982 reported associations in the opposite direction.

The extensive review by Poole et al. ${ }^{(5)}$ reviewed in detail 47 distinct studies on SES and the risk of childhood leukaemia. About half of these found a positive and the other half a negative association between SES and the risk of leukaemia, whereas a few studies found no evidence for an association. The direction of the association differed according to the study design and the SES measure used: if the parents' level of education was considered, the studies showed predominantly negative associations (i.e. higher rates associated with lower SES), whereas occupational class was usually positively associated with SES (i.e. higher rates associated with higher SES). Registry- and record-based studies generally produced positive associations, whereas interviewbased case-control studies showed negative associations. There was also some temporal heterogeneity, with more positive associations in older studies and negative associations in newer studies.

Looking at these studies, the types of study design and SES measures used in different parts of the world and at different time periods were so highly correlated with each other that it was impossible to disentangle their separate effects. For instance, no
US study published after 1970 used father's occupational class, and no European study used family income and almost none of the case-control or cohort studies used an area-based SES measure. This homogeneity within groups did not allow to examine separately the effect of study design, population characteristics and SES measure on the direction of the results ${ }^{(5)}$.

The authors concluded that selection bias related to SES might be a major cause underlying the heterogeneous results, with case-control studies including most cases, but only a selected subset of all relevant controls, resulting in an over-representation of highSES controls. In contrast, registry-based studies might suffer from a tendency to under-represent cases from lower social class ${ }^{(5,32)}$. Therefore, they recommended performing validation studies to estimate SES-related selection and participation. Because different SES measures (such as income and education) and individual-level and area-level measures may represent different risk factors, they also advised researchers to report these measures separately rather than in summary indices of social class.

\section{METHODS}

\section{Recent publications on SES and childhood leukaemia (September 2002-April 2008)}

A full text literature search was performed in PubMed for studies published from September 2002 through April 2008 for original research in English, using the MeSH terms ('Leukaemia' or 'Leukaemia/diagnosis' or 'Leukaemia/drug effects') and ('Socioeconomic Factors') and ('Risk Factors') and ('Humans') and ('infant' or 'child' or 'adolescent'). In addition to the MeSH terms, the following keywords were used: ('leukaemia' or 'leukaemias' or 'leukaemia' or 'leukaemias') or ('risk factor' or 'risk factors' or 'risk' or 'risks' or 'factor' or 'factors') and ('social class' or 'SES' or 'socioeconomic factors' or 'socioeconomic').

For this review, only studies were retained that compared leukaemia incidence or mortality for children or adolescents (aged 0-20 y) and used one of the following SES measures as exposure: paternal or maternal education, parental occupational class and employment, family income, housing characteristics and area-level SES indicators. Excluded were: (1) studies using SES measures only for adjustment in a multivariable model with another main exposure of interest and not reporting detailed results for SES; (2) studies dealing with exposures that are associated with SES, but more closely represent risk factors considered in other reviews published in this issue of the journal (such as urbanisation, residential mobility, parental professional exposures to toxicants, sibship size or parental social contacts) and (3) studies from developing countries where the 


\section{SES AND CHILDHOOD LEUKAEMIA}

meaning of different SES measures might differ fundamentally from developed countries. The studies were reviewed with regard to study design (case-control, cross-sectional and cohort studies), study population (hospital-based or populationbased), SES measures used, time trends, the availability of subgroup analyses for different age groups, leukaemia subtypes and timing of exposure (at birth, at the time of diagnosis) and the potential for ascertainment bias.

\section{RESULTS}

The PubMed search returned 83 citations. Thirteen publications which had a different paper format (review, meta-analysis, letter, editorial or methodological paper), 33 papers in which the outcome was not leukaemia incidence, but rather access to treatment, diagnostic work-up or survival, and 30 papers in which the results for SES were not reported separately, but where SES was only used for adjustment, were excluded. The authors ended up with seven papers which conformed with their inclusion criteria $^{(35-39)}$.

Tables 1 and 2 describe the characteristics of these studies and the main results. With the exception of one ecological study from the USA ${ }^{(35)}$, all other papers were based on large population-based cohort or case-control studies, linking data from highquality national cancer registries to national census data or representative population-based cohorts, with relatively little potential for ascertainment bias. Two ${ }^{(33,36)}$ included a large proportion of children diagnosed in later childhood or young adulthood and were therefore rather difficult to compare with the others, which focused on leukaemia or acute lymphoid leukaemia (ALL) in young children. Four of them ${ }^{(34-36,38)}$ utilised only area-based measures of SES, one ${ }^{(33)}$ utilised only family-based measures and two ${ }^{(37,39)}$ could compare both and were also able to compare the effects of SES at birth in comparison to SES at the time of diagnosis.

Even when comparing the four relatively comparable recent studies which used an area-based measure of SES (Table 3), the results were heterogeneous. Two suggested a relative protection of children living in the most deprived area ${ }^{(34,38)}$, one suggested an increased risk in this group (for residence at birth only ${ }^{(39)}$ ) and one showed no effect ${ }^{(37)}$. However, overall, the effect sizes were small and only evident in the most extreme quantiles (Table 3 ).

\section{Association with time of exposure}

One of the two studies comparing residence at birth and residence at diagnosis found only an association with residence at the time of birth, suggesting that factors acting early in life might be important ${ }^{(39)}$.
The other study comparing the two time points of exposure found no association with either ${ }^{(37)}$.

\section{Comparison of different SES measures}

Raaschou-Nielsen et al. found only an association with area-based, but not with family-based measures of SES (job titles of parents) and concluded that community behaviour rather than individual lifestyle might be important. Unfortunately, most studies could only utilise one or few different SES measures.

\section{Association with age at diagnosis}

Three of the four studies which analysed different age groups separately found an association only (or stronger) for 1-4-y olds but none for older children $^{(34,35,39)}$, whereas Smith et al. ${ }^{(37)}$ did not find any age differences.

\section{Association with leukaemia subtype}

Results comparing effects in different leukaemia subtypes were heterogeneous, with two studies suggesting an association mainly for acute myeloid leukaemia $(\mathrm{AML})^{(33,39)}$, one mainly for chronic myeloid leukaemia $(\mathrm{CML})^{(36)}$ and Borugian et al. found the strongest effect in ALL patients ${ }^{(38)}$.

\section{Time trends}

The two studies which explicitly analysed potential time trends did not find any evidence supporting these ${ }^{(38,39)}$.

\section{DISCUSSION}

\section{Methodological considerations: role of case and control ascertainment bias}

All reviewed papers, with the exception of one ecological study ${ }^{(35)}$, describe large population-based cohort or case-control studies, linking data from high-quality national cancer registries to representative datasets. Therefore, the potential for bias induced by relative under ascertainment of controls and/or cases is less compared with earlier publications which were often based on hospital-based case-control studies ${ }^{(5)}$.

A thorough illustration of the impact of ascertainment bias of cases and controls on the direction of the results has been given by Smith et al. ${ }^{(37)}$, using data from the United Kingdom Childhood Cancer Study. This study included all children diagnosed with cancer in the UK between 1991 and 1996 and random controls from primary-care population registries. The proactive rapid case-finding system established for this study allowed to include $10 \%$ 
Table 1. Characteristics of studies on childhood leukaemia and SES: study design and population.

\begin{tabular}{|c|c|c|c|c|c|c|c|}
\hline First author, year & Location & Period $^{\mathrm{a}}$ & Outcome & Design & Cases & Controls/cohort & Number of cases \\
\hline Paltiel, $2004^{(33)}$ & Israel & $1964-99$ & $\begin{array}{l}\text { Leukaemia } \\
\text { incidence }\end{array}$ & Cohort study & $\begin{array}{l}\text { All cases reported to Israel's Cancer } \\
\text { Registry (aged } 0-35 \mathrm{y} \text { ) }\end{array}$ & $\begin{array}{l}\text { Population-based research } \\
\text { cohort of } 88829 \text { children } \\
\text { (Jerusalem Perinatal study) }\end{array}$ & $\begin{array}{l}65 \text { with } \\
\text { leukaemia }\end{array}$ \\
\hline $\begin{array}{l}\text { Raaschou- } \\
\text { Nielsen, 2004 }\end{array}$ & Denmark & 1976-91 & $\begin{array}{l}\text { Leukaemia } \\
\text { incidence }\end{array}$ & $\begin{array}{l}\text { Population-based } \\
\text { matched case-- } \\
\text { control study }\end{array}$ & $\begin{array}{l}\text { All children aged } 0-14 \text { y with } \\
\text { leukaemia reported to the Danish } \\
\text { Cancer Registry }\end{array}$ & $\begin{array}{l}\text { From Central Population } \\
\text { Registry, matched for age, } \\
\text { sex and time of birth }\end{array}$ & $\begin{array}{l}377 \text { with } \\
\text { leukaemia }\end{array}$ \\
\hline $\begin{array}{l}\text { Borugian, } \\
2005^{(38)}\end{array}$ & Canada & $1985-2001$ & $\begin{array}{l}\text { Leukaemia } \\
\text { incidence }\end{array}$ & $\begin{array}{l}\text { National cohort } \\
\text { study }\end{array}$ & $\begin{array}{l}\text { All children aged } 0-19 \text { y with } \\
\text { leukaemia reported to the population- } \\
\text { based cancer registries in Canada }\end{array}$ & $\begin{array}{l}\text { Person-years at risk derived } \\
\text { from } 1991 \text { census }\end{array}$ & $\begin{array}{l}5240 \text { with } \\
\text { leukaemia }\end{array}$ \\
\hline Smith, $2006^{(37)}$ & UK & $1991-96$ & $\begin{array}{l}\text { Leukaemia } \\
\text { incidence }\end{array}$ & $\begin{array}{l}\text { Population-based } \\
\text { case-control study }\end{array}$ & $\begin{array}{l}\text { All leukaemia cases aged } 0-14 \text { y } \\
\text { ascertained via rapid hospital-based } \\
\text { case-finding system (UK childhood } \\
\text { cancer study) }\end{array}$ & $\begin{array}{l}\text { From primary-care } \\
\text { population registries }\end{array}$ & $\begin{array}{l}1910 \text { with } \\
\text { leukaemia, } 1578 \\
\text { with ALL }\end{array}$ \\
\hline Alston, $2007^{(36)}$ & England & $1979-2001$ & $\begin{array}{l}\text { Leukaemia } \\
\text { incidence }\end{array}$ & Cohort study & $\begin{array}{l}\text { All adolescents and young adults } \\
\text { (aged } 13-24 \text { y) registered in the } \\
\text { National Cancer Registry }\end{array}$ & $\begin{array}{l}\text { Person-years at risk derived } \\
\text { from census data }\end{array}$ & $\begin{array}{l}3935 \text { with } \\
\text { leukaemia }\end{array}$ \\
\hline $\begin{array}{l}\text { Adelman, } \\
2007^{(35)}\end{array}$ & USA & $1992-98$ & $\begin{array}{l}\text { ALL } \\
\text { incidence }\end{array}$ & $\begin{array}{l}\text { Ecological study } \\
\text { (county level) }\end{array}$ & $\begin{array}{l}\text { All incident ALL cases in children } \\
\text { aged } 0-4 \text { y from cancer registries }\end{array}$ & $\begin{array}{l}\text { Person-years at risk from } \\
\text { routine data }\end{array}$ & 836 with ALL \\
\hline Stiller, $2008^{(34)}$ & UK & $1986-95$ & $\begin{array}{l}\text { ALL } \\
\text { incidence }\end{array}$ & $\begin{array}{l}\text { National cohort } \\
\text { study }\end{array}$ & $\begin{array}{l}\text { All incident ALL cases in children } \\
\text { aged } 0-14 \text { y in England and Wales }\end{array}$ & $\begin{array}{l}\text { Person-years at risk derived } \\
\text { from } 1991 \text { census }\end{array}$ & 3150 with ALL \\
\hline
\end{tabular}

This table includes studies published from September 2002 to April 2008. ALL, acute lymphoid leukaemia

${ }^{a}$ Period, year of diagnosis. 
Table 2. Characteristics of studies on childhood leukaemia and SES: SES measures, analysis and results.

\begin{tabular}{|c|c|c|c|c|c|c|}
\hline \multirow[t]{2}{*}{ First author, year } & \multirow{2}{*}{$\begin{array}{l}\text { Level and type of SES } \\
\text { measures }\end{array}$} & \multicolumn{4}{|c|}{ Subgroup analysis } & \multirow[t]{2}{*}{ Conclusions } \\
\hline & & Exposure time & $\begin{array}{l}\text { Leukaemia } \\
\text { subtypes }\end{array}$ & Age at diagnosis & Time trends & \\
\hline Paltiel, 2004 ${ }^{(33)}$ & $\begin{array}{l}\text { Father's occupation at birth, } \\
\text { father's education at birth, } \\
\text { mother's education at birth }\end{array}$ & Birth & $\begin{array}{l}\text { Yes, association } \\
\text { only found for } \\
\text { AML }\end{array}$ & Not done & Not done & $\begin{array}{l}\text { Increased risk of AML with higher } \\
\text { paternal occupation (only significant in } \\
\text { unadjusted analysis) }\end{array}$ \\
\hline $\begin{array}{l}\text { Raaschou- } \\
\text { Nielsen, 2004 }\end{array}$ & $\begin{array}{l}\text { Municipality income at } \\
\text { birth, municipality income } \\
\text { at diagnosis, parental } \\
\text { occupation (job title) }\end{array}$ & $\begin{array}{l}\text { Birth and diagnosis } \\
\text { association only } \\
\text { with exposure at } \\
\text { birth }\end{array}$ & $\begin{array}{l}\text { Yes (stronger for } \\
\text { AML) }\end{array}$ & $\begin{array}{l}\text { Yes (stronger for } \\
1-4 \text {-y olds) }\end{array}$ & Yes (none found) & $\begin{array}{l}\text { (1) Increased risk of leukaemia in } \\
\text { children born in deprived communities } \\
\text { (2) Community characteristics more } \\
\text { important than individual lifestyle } \\
\text { (3) These factors act early in life }\end{array}$ \\
\hline $\begin{array}{l}\text { Borugian, } \\
2005^{(38)}\end{array}$ & $\begin{array}{l}\text { Area-based income quintiles } \\
\text { at diagnosis (from census } \\
\text { data) }\end{array}$ & Diagnosis & $\begin{array}{l}\text { Yes (association } \\
\text { only found for } \\
\text { ALL) }\end{array}$ & Yes (none found) & Yes (none found) & $\begin{array}{l}\text { Slightly lower risk in poorest income } \\
\text { quintile }\end{array}$ \\
\hline Smith, $2006^{(37)}$ & $\begin{array}{l}\text { Area-based deprivation } \\
\text { score at birth, area-based } \\
\text { deprivation score at } \\
\text { diagnosis, father's } \\
\text { occupation at birth }\end{array}$ & $\begin{array}{l}\text { Birth and diagnosis } \\
\text { no association } \\
\text { found at either } \\
\text { time point }\end{array}$ & $\begin{array}{l}\text { Only ALL and } \\
\text { all leukaemias } \\
\text { considered }\end{array}$ & Not done & Not done & $\begin{array}{l}\text { SES is not a determinant of ALL in } \\
\text { children. Different results are obtained } \\
\text { by (simulated) case or control selection } \\
\text { bias }\end{array}$ \\
\hline Alston, $2007^{(36)}$ & $\begin{array}{l}\text { Area-based deprivation } \\
\text { score (Townsend Index) }\end{array}$ & Diagnosis & $\begin{array}{l}\text { Yes (association } \\
\text { strongest for } \\
\text { CML) }\end{array}$ & Not done & Not done & $\begin{array}{l}\text { Higher CML risk in more deprived } \\
\text { wards }\end{array}$ \\
\hline $\begin{array}{l}\text { Adelman, } \\
2007^{(35)}\end{array}$ & $\begin{array}{l}\text { Proportion of households } \\
\text { with low income in county } \\
\text { (1989 census) }\end{array}$ & Undefined & $\begin{array}{l}\text { Only ALL } \\
\text { included }\end{array}$ & Only $0-4-y$ olds & Not done & $\begin{array}{l}\text { Increased ALL risk in females (but not } \\
\text { males) of more affluent counties }\end{array}$ \\
\hline Stiller, $2008^{(34)}$ & $\begin{array}{l}\text { Area-based deprivation } \\
\text { score (Carstairs Index, } 1991 \\
\text { census) }\end{array}$ & Diagnosis & $\begin{array}{l}\text { Only ALL } \\
\text { included }\end{array}$ & $\begin{array}{l}\text { Yes (association } \\
\text { only found for } \\
1-4-y \text { olds) }\end{array}$ & Not done & $\begin{array}{l}\text { Slightly decreased risk of ALL in most } \\
\text { deprived quintile (1-4-y olds only, } \\
\text { suggesting an association with precursor } \\
\text { B-cell ALL) }\end{array}$ \\
\hline
\end{tabular}

This table includes studies published from September 2002 to April 2008. ALL, acute lymphoid leukaemia; AML, acute myeloid leukaemia; CML, chronic myeloid leukaemia 
M. ADAM ET AL.

Table 3. Association between risk of childhood leukaemia and area-based indicators of SES.

\begin{tabular}{|c|c|c|c|c|c|c|}
\hline \multirow[t]{2}{*}{ First author } & \multirow{2}{*}{$\begin{array}{c}\text { Exposure } \\
\text { time }\end{array}$} & \multicolumn{5}{|c|}{ Area-based SES measure (quantiles) } \\
\hline & & 1 (most affluent) & 2 & 3 & 4 & 5 (most deprived) \\
\hline \multirow[t]{2}{*}{ Smith $^{\mathrm{a}}$} & At birth & 1 & $1.00(0.85-1.18)$ & $0.88(0.74-1.04)$ & $0.96(0.81-1.13)$ & $0.92(0.78-1.07)$ \\
\hline & At diagnosis & 1 & $1.06(0.90-1.24)$ & $0.92(0.78-1.08)$ & $1.03(0.88-1.21)$ & $0.96(0.82-1.13)$ \\
\hline \multirow{4}{*}{$\begin{array}{l}\text { Stiller } \\
\text { Borugian }^{\mathrm{c}} \\
\text { Raaschou- } \text { Nielsen }^{\mathrm{d}}\end{array}$} & At diagnosis & 1 & 1.02 & 1.01 & 0.99 & $0.87(P=0.007)$ \\
\hline & At diagnosis & 1 & $0.92(0.84-1.00)$ & $0.97(0.89-1.05)$ & $0.96(0.88-1.04)$ & $0.87(0.80-0.95)$ \\
\hline & At birth & $0.81(0.51-1.29)$ & & 1 & & $2.71(1.41-5.21)$ \\
\hline & At diagnosis & $0.97(0.61-1.56)$ & & 1 & & $0.89(0.47-1.70)$ \\
\hline
\end{tabular}

${ }^{a}$ Area-based deprivations score.

${ }^{\mathrm{b}}$ Carstairs deprivation score; only ALL cases included.

${ }^{\mathrm{c}}$ Neighbourhood-based income quintiles.

${ }^{\mathrm{d}}$ Average community income (contrasting the lowest and highest $10 \%$ with the middle $80 \%$ ).

more cases compared with regular cancer registration in the years before and after the study period. The main analysis, which did not rely on participation of either cases nor controls, found no association between leukaemia and the area-based deprivation score at birth [odds ratio (OR), comparing the risk of leukaemia in those born in the most deprived, compared with the least deprived quintile $0.92(95 \%$ CI $0.78-1.07)]$ or at the time of diagnosis [OR $0.96(0.82-1.13)]$. The authors then performed a first sensitivity analysis, which included only those cases who participated in the interview for the late effects study, but all selected controls. This analysis, which simulated a case ascertainment bias, resulted in a (spurious) positive association with SES (less leukaemia in deprived families), with an OR of 0.77 (0.63-0.94) comparing the most deprived to the least deprived quintile at the time of birth. Second, the authors performed a sensitivity analysis including only cases and controls taking part in the interview. This analysis resulted in a spurious negative association between SES and leukaemia (more leukaemia in deprived families), because relatively more controls, and especially more deprived controls, refused to participate. The OR for leukaemia, comparing the most deprived to the least deprived, was $1.08(0.92-1.28)$ at birth and $1.21(1.02-1.43)$ at diagnosis. They also showed that a large proportion of cases and controls had moved house between time of birth and time of diagnosis, usually to better neighbourhoods. This illustrates the transient nature of area-based measures of SES and emphasises the importance of measuring SES variables at the same time points for cases and the comparison group. The obvious discrepancy of the main results of this study with those from the other UK-based study (using an overlapping data set) ${ }^{(34)}$, which found a protective effect of residence in the most deprived neighbourhood quintile, might perhaps be explained by a small degree of case under ascertainment, as the UK Childhood Cancer Registry contains in average $\sim 10 \%$ less cases than those recruited for the United Kingdom Childhood Cancer Study. The same might apply for the study in Canada, which again is based on complete data for controls, but might suffer from a small degree of case under ascertainment ${ }^{(38)}$.

\section{SUMMARY AND CONCLUSIONS}

In summary, the results both from studies published prior to 2003 and from more recent large scale representative cohort or case-control studies are heterogeneous, and there is no clear evidence to support an association between SES and incidence of leukaemia in childhood. A number of factors, most importantly case and control selection bias, might explain inconsistencies between published studies. Overall, there is some support for an association between SES at birth (rather than later in childhood) and childhood leukaemia. Effect sizes were, however, small and usually restricted to the most extreme groups (the 10 or $20 \%$ with highest or lowest deprivation). This makes it unlikely that SES would act as a strong confounder in research addressing associations between other exposures and childhood leukaemia.

Future studies should make efforts to avoid even small degrees of case and control participation bias, to compare different SES measures acting at different times during the life course (birth, infancy, childhood) and to assess potential interactions with age at diagnosis and leukaemia subtypes. This might help to unravel potential causative factors for childhood leukaemia. 


\section{SES AND CHILDHOOD LEUKAEMIA}

\section{FUNDING}

Claudia Kuehni was funded by the Swiss National Science Foundation (PROSPER Grant 3233-069348) and Martin Adam by the Swiss Cancer League (KLS 01605-10-2004) and the Bernese Cancer League.

\section{ACKNOWLEDGEMENT}

The authors would like to thank an anonymous reviewer for constructive comments on a previous version of this manuscript.

\section{REFERENCES}

1. Arntzen, A., Samuelsen, S. O., Bakketeig, L. S. and Stoltenberg, C. Socioeconomic status and risk of infant death. A population-based study of trends in Norway, 1967-1998. Int. J. Epidemiol. 3(2), 279-288 (2004).

2. Huisman, M. et al. Educational inequalities in causespecific mortality in middle-aged and older men and women in eight western European populations. Lancet 365(9458), 493-500 (2005).

3. Saxena, S., Majeed, A. and Jones, M. Socioeconomic differences in childhood consultation rates in general practice in England and Wales: prospective cohort study. Br. Med. J. 318(7184), 642-646 (1999).

4. Greenberg, R. S. and Shuster, J. L. Jr. Epidemiology of cancer in children. Epidemiol. Rev. 7, 22-48 (1985).

5. Poole, C., Greenland, S., Luetters, C., Kelsey, J. L. and Mezei, G. Socioeconomic status and childhood leukaemia: a review. Int. J. Epidemiol. 35(2), 370-384 (2006).

6. Krieger, N., Williams, D. R. and Moss, N. E. Measuring social class in US public health research: concepts, methodologies, and guidelines. Annu. Rev. Public Health 18, 341-378 (1997).

7. Ben-Shlomo, Y. and Smith, G. D. Deprivation in infancy or in adult life: which is more important for mortality risk? Lancet 337(8740), 530-534 (1991).

8. Kuh, D., Ben-Shlomo, Y., Lynch, J., Hallqvist, J. and Power, C. Life course epidemiology. J. Epidemiol. Community Health 57(10), 778-783 (2003).

9. Ben-Shlomo, Y. and Kuh, D. A life course approach to chronic disease epidemiology: conceptual models, empirical challenges and interdisciplinary perspectives. Int. J. Epidemiol. 31(2), 285-293 (2002).

10. Galobardes, B., Shaw, M., Lawlor, D. A., Lynch, J. W. and Davey Smith, G. Indicators of socioeconomic position (part 1). J. Epidemiol. Community Health 60(1), 7-12 (2006)

11. Galobardes, B., Shaw, M., Lawlor, D. A., Lynch, J. W. and Davey Smith, G. Indicators of socioeconomic position (part 2). J. Epidemiol. Community Health 60(2), 95-101 (2006).

12. Lynch, J. and Kaplan, G. Socioeconomic position. In: Social Epidemiology. Berkman, L. F. and Kawachi, I., Eds. (Oxford: Oxford University Press) pp. 13-35 (2000).

13. Sausenthaler, S., Kompauer, I., Mielck, A., Borte, M., Herbarth, O., Schaaf, B., von Berg, A. and Heinrich, J. Impact of parental education and income inequality on children's food intake. Public Health Nutr. 10(1), 24-33 (2007).

14. Liberatos, P., Link, B. G. and Kelsey, J. L. The measurement of social class in epidemiology. Epidemiol. Rev. 10, 87-121 (1988).

15. Backlund, E., Sorlie, P. D. and Johnson, N. J. The shape of the relationship between income and mortality in the United States. Evidence from the National Longitudinal Mortality Study. Ann. Epidemiol. 6(1), 12-20 (1996); discussion 21-22.

16. Lynch, J. W., Kaplan, G. A. and Shema, S. J. Cumulative impact of sustained economic hardship on physical, cognitive, psychological, and social functioning. N. Engl. J. Med. 337(26), 1889-1895 (1997).

17. Howden-Chapman, P. Housing standards: a glossary of housing and health. J. Epidemiol. Community Health 58(3), 162-168 (2004).

18. Jarman, B. Identification of underprivileged areas. $\mathrm{Br}$. Med. J. (Clin. Res. Ed.) 286(6379), 1705-1709 (1983).

19. Carstairs, V. and Morris, R. Deprivation and health in Scotland. Health Bull. (Edinb.) 48(4), 162-175 (1990).

20. Townsend, P., Philimore, P. and Beattie, A. Health and Deprivation: Inequality and the North (Bristol: Croom Helm) (1988).

21. Eames, M., Ben-Shlomo, Y. and Marmot, M. G. Social deprivation and premature mortality: regional comparison across England. Br. Med. J. 307(6912), 1097-1102 (1993).

22. Carstairs, V. and Morris, R. Deprivation: explaining differences in mortality between Scotland and England and Wales. Br. Med. J. 299(6704), 886-889 (1989).

23. Jordan, H., Roderick, P. and Martin, D. The Index of Multiple Deprivation 2000 and accessibility effects on health. J. Epidemiol. Community Health 58(3), 250-257 (2004).

24. Woods, L. M., Rachet, B., Riga, M., Stone, N., Shah, A. and Coleman, M. P. Geographical variation in life expectancy at birth in England and Wales is largely explained by deprivation. J. Epidemiol. Community Health 59(2), 115-120 (2005).

25. Krieger, N. Overcoming the absence of socioeconomic data in medical records: validation and application of a census-based methodology. Am. J. Public Health 82(5), 703-710 (1992).

26. Yeracaris, C. A. and Kim, J. H. Socioeconomic differentials in selected causes of death. Am. J. Public Health 68(4), 342-351 (1978).

27. Jenkins, C. D., Tuthill, R. W., Tannenbaum, S. I. and Kirby, C. R. Zones of excess mortality in Massachusetts. N. Engl. J. Med. 296(23), 1354-1356 (1977).

28. Wise, P. H., Kotelchuck, M., Wilson, M. L. and Mills, M. Racial and socioeconomic disparities in childhood mortality in Boston. N. Engl. J. Med. 313(6), 360-366 (1985).

29. Wing, S., Barnett, E., Casper, M. and Tyroler, H. A. Geographic and socioeconomic variation in the onset of decline of coronary heart disease mortality in white women. Am. J. Public Health 82(2), 204-209 (1992).

30. Laveist, T. A. Segregation, poverty, and empowerment: health consequences for African Americans. Milbank Q. 71(1), 41-64 (1993).

31. Smith, G. D., Bartley, M. and Blane, D. Black on class and health: a reply to strong. J. Public Health Med. 13(4), 350-359 (1991).

32. Kuehni, C. E. and Zwahlen, M. Commentary: numerous, heterogeneous, and often poor-the studies on 


\section{ADAM ET AL.}

childhood leukaemia and socioeconomic status. Int. J. Epidemiol. 35(2), 384-385 (2006).

33. Paltiel, O., Harlap, S., Deutsch, L., Knaanie, A., Massalha, S., Tiram, E., Barchana, M. and Friedlander, Y. Birth weight and other risk factors for acute leukemia in the Jerusalem Perinatal Study cohort. Cancer Epidemiol. Biomarkers Prev. 13(6), 1057-1064 (2004).

34. Stiller, C. A., Kroll, M. E., Boyle, P. J. and Feng, Z. Population mixing, socioeconomic status and incidence of childhood acute lymphoblastic leukaemia in England and Wales: analysis by census ward. Br. J. Cancer 98(5), 1006-1011 (2008).

35. Paltiel, O., Harlap, S., Deutsch, L., Knaanie, A., Massalha, S., Tiram, E., Barchana, M. and Friedlander, Y. Residential mobility and risk of childhood acute lymphoblastic leukaemia: an ecological study. Br. J. Cancer 97(1), 140-144 (2007).
36. Alston, R. D., Rowan, S., Eden, T. O., Moran, A. and Birch, J. M. Cancer incidence patterns by region and socioeconomic deprivation in teenagers and young adults in England. Br. J. Cancer 96(11), 1760-1766 (2007).

37. Smith, A., Roman, E., Simpson, J., Ansell, P., Fear, N. T. and Eden, T. Childhood leukaemia and socioeconomic status: fact or artefact? A report from the United Kingdom Childhood Cancer Study (UKCCS). Int. J. Epidemiol. 35(6), 1504-1513 (2006).

38. Borugian, M. J., Spinelli, J. J., Mezei, G., Wilkins, R., Abanto, Z. and McBride, M. L. Childhood leukemia and socioeconomic status in Canada. Epidemiology 16(4), 526-531 (2005).

39. Raaschou-Nielsen, O., Obel, J., Dalton, S., TjOnneland, A. and Hansen, J. Socioeconomic status and risk of childhood leukaemia in Denmark. Scand J. Public Health 32(4), 279-286 (2004). 